\title{
A CONSULTORIA CONTÁBIL ADMINISTRATIVA: UMA NOVA FORMA DE CONDUZIR UMA EMPRESA VIA TECNOLOGIA
}

\section{ARTIGO ORIGINAL}

SUMAR, Ramiro Rodrigues ${ }^{1}$

SUMAR, Ramiro Rodrigues. A consultoria contábil administrativa: uma nova forma de conduzir uma empresa via tecnologia. Revista Científica Multidisciplinar Núcleo do Conhecimento. Ano 06, Ed. 07, Vol. 12, pp. 91-104. Julho de 2021. ISSN: 2448-0959, Link de acesso:

https://www.nucleodoconhecimento.com.br/administracao/empresa-via-tecnologia, DOI: 10.32749/nucleodoconhecimento.com.br/administracao/empresa-via-tecnologia

\section{RESUMO}

Objetivo: Descrever o impacto a partir dos obstáculos e potencialidades que a tecnologia trouxe para a consultoria contábil. Pergunta problema: Como a consultoria contábil administrativa pode ajudar uma empresa utilizando as tecnologias? Métodos: O estudo trata-se de uma revisão bibliográfica. Foi realizado uma busca com os descritores: tecnologia; inovação; contabilidade; contabilidade consultiva, na plataforma de dados da Spell (Scientific Periodicals Eletronic Library) em junho de 2021. A busca resultou em 10 artigos. Resultados: os resultados trouxeram como obstáculos: O crescente avanço tecnológico, adequar ao uso dessas novas tecnologias, Centralidade do papel do contador nos tradicionais modelos, Falta de conhecimento de software, Falta de força de trabalho especializada, mau funcionamento da conexão, Mão de obra qualificada. E como potencialidades: Utilização de diferentes tecnologias digitais, Agilidade e ganho de tempo, Comodidade, Relação indissociável entre a tecnologia e a contabilidade

\footnotetext{
${ }^{1}$ Mestrando em Controladoria, Especialista em Gestão de Tecnologia, Administração estratégica, Segurança da informação e Graduado em Ciências Contábeis.
}

RC: 92519

Disponível em: https://www.nucleodoconhecimento.com.br/administracao/empresa- 
consultiva promovendo suporte ágil e de qualidade aos seus diversos usuários, Satisfação do cliente, Velocidade e flexibilidade e Redução de custos. Conclusões: Entende-se que as Tecnologias de Informação influenciam positivamente no exercício da contabilidade consultiva, muito embora que além das vantagens tenha as suas desvantagens. Cabe destacar que as tecnologias viabilizam o controle das informações contábeis de entrada e saída de materiais e insumos, bem como sua origem e destino final, evitando perdas desnecessárias, inclusive com desvios, agilidade, flexibilidade e segurança.

Palavras-chave: Consultoria, Inovação, Meios tecnológicos, Segurança na informação.

\section{INTRODUÇÃO}

O elo de relação da contabilidade com as tecnologias já perpetua por décadas, visto que, além de ser ciência, a contabilidade é um dos sistemas de informação utilizados na gestão empresarial mais antigo, o que torna diferente a contabilidade do passado e a contabilidade do presente são as formas que elas conduzem a gestão empresarial (FERREIRA et al., 2017).

A tecnologia vem avançando no decorrer dos anos, inovando para que a necessidade do ser humano seja suprida. Portanto, sendo uma ferramenta ilimitada, a evolução das tecnologias aliada a contabilidade traz contribuições relevantes para o crescimento das organizações (SILVA et al., 2020).

O uso contínuo das redes de computadores e a combinação de diversos instrumentos da contabilidade favorecem o armazenamento, registro, processamento e facilita a realização do cruzamento de informações cada vez mais rápido o que possibilita na tomada de decisões mais segura dentro da organização (MARION; RIBEIRO, 2017; DE ANDRADE SIMÕES et al., 2021).

RC: 92519

Disponível em: https://www.nucleodoconhecimento.com.br/administracao/empresa- 
Atualmente a busca de informação vem sendo útil e ao mesmo tempo relevante para o crescimento da organização. A transferência da informação para o conhecimento, bem como a aplicação oportuna do conhecimento em prática e a distribuição destes atos para o desenvolvimento de uma empresa, são potencialidades da tecnologia em prol da contabilidade consultiva para o empreendedor.

Entretanto, muitos contadores não utilizam esta ferramenta como forma de ganhar espaço, tempo e fidelizar seus clientes, deixando claro que em algumas situações, as tecnologias para os contadores não são utilizadas. Nesta colocação, identificando a problematização do estudo em questão, tem-se a pergunta que norteou o tema deste estudo: Como a consultoria contábil administrativa pode ajudar uma empresa utilizando as tecnologias?

O mercado de trabalho atual, muitas vezes motiva as pessoas a se reformularem nas suas atividades profissionais, pois o sistema de ensino básico universitário e os novos conhecimentos ainda se tornam poucos frente à prática que o aluno irá desempenhar após estar formado.

Segundo Villa et al (2012, p.107), "os contadores tradicionais têm uma visão de que os empreendedores, não buscam o conhecimento necessário à gestão de seus negócios, ou seja, não realizam cursos de aperfeiçoamento ou treinamento em administração". Parafraseando esta citação do autor, indica que o empreendedor apenas tem o interesse de atender as demandas dos impostos, esquecendo assim, do mercado competitivo, o que faz com que a empresa perca espaço e não se desenvolva na sua qualidade.

Nesta colocação observa-se a importância do contador consultivo. Este trabalho se agrega na justificativa do pesquisador de compreender o porquê muitos contadores não utilizam da contabilidade consultiva para trabalhar com seus clientes, visto que, esta ferramenta de ajuda em especial nos tempos de pandemia do novo coronavírus

RC: 92519

Disponível em: https://www.nucleodoconhecimento.com.br/administracao/empresa- 
exerce influência para que a empresa não esteja correndo o risco de ter comprometimento em seus rendimentos no mercado competitivo.

Logo, torna-se relevante 0 assunto, pois com 0 advento das tecnologias, a contabilidade das empresas tomou um direcionamento diferente da contabilidade de décadas atrás e com isso, o contador, agora, tem a responsabilidade e o compromisso de fazer com que sua profissão seja identificada pela sociedade e pelos empreendedores como uma profissão que está avançando para adequar-se aos meios tecnológicos em prol de garantir mais segurança e confiabilidade às organizações.

Portanto, esse trabalho tem como objetivo geral: Descrever o impacto a partir dos obstáculos e potencialidades que a tecnologia trouxe para a consultoria contábil.

\section{PROCESSO METODOLÓGICO}

Este estudo é uma revisão bibliográfica sistemática de carácter qualitativo. Segundo Sampaio e Mancini (2007) este tipo de estudo é realizado por meio de busca de artigos pertinentes a temática pesquisada, baseando-se na síntese dos assuntos relevantes combinado com métodos sistematizados de investigação, análise crítica, resumo das informações escolhidas e problemas importantes que necessitem de novos estudos.

Para a realização da pesquisa foram seguidas as seguintes etapas recomendas por Sampaio e Mancini (2007): Formulação da pergunta norteadora do estudo; Localização dos estudos; Avaliação crítica dos estudos; Coleta de dados; Análise dos dados; Aspectos éticos.

A partir da construção de uma pergunta norteadora, surgem alguns pressupostos que nortearam e/ou delimitaram esse estudo, possibilitando assim, destacar a aplicabilidade das tecnologias no universo da consultoria dos números e valores a

RC: 92519

Disponível em: https://www.nucleodoconhecimento.com.br/administracao/empresa- 
qual o contador está inserido. A pergunta que norteou o tema foi: Como a consultoria contábil administrativa pode ajudar uma empresa utilizando as tecnologias?

O material foi selecionado nas bases de dados: Spell (Scientific Periodicals Eletronic Library). A amostra do estudo foi composta por artigos (pesquisa original; artigos de revisão; monografias, teses e dissertações). Foram utilizados como critérios de inclusão artigos em língua portuguesa e inglesa, dentre os anos 2016 a 2020 que estejam disponíveis na integra e gratuitos. Todos os artigos que estivessem enquadrados nestes critérios, que em sua área de conhecimento abrangesse a contabilidade e tivesse como título ou resumo assuntos pertinentes ao uso das tecnologias foram enquadrados para a pesquisa. Foram excluídos os demais artigos que não estivessem enquadrados na inclusão ou estivessem duplicados. As palavras-chave utilizadas para a busca destes artigos na Spell foram: tecnologia; inovação; contabilidade; contabilidade consultiva.

A avaliação crítica das produções que foram selecionadas e incluídas no estudo fez surgir interpretações e a síntese dos resultados, identificando as informações científicas presentes em cada estudo e os fatores relevantes para o estudo em questão sugerindo pautas para pesquisas futuras. Para validação do estudo, o pesquisador deixa claro quais lacunas foram encontradas no estudo e quais caminhos futuros outros pesquisadores podem adotar em suas pesquisas científicas. As principais informações foram dispostas em quadros, deixando claras as informações pertinentes aos resultados dos artigos, confrontando os assuntos com a literatura pertinente ao tema.

A coleta de dados foi realizada durante o mês de junho de 2021. A coleta foi realizada incluindo os critérios de inclusão e exclusão dos artigos. Ressaltando ainda que a pesquisa também busca, com base na análise realizada, relatar sobre a contabilidade consultiva e o uso das tecnologias. Foram feitas duas buscas intercalando as palavras-chaves.

RC: 92519

Disponível em: https://www.nucleodoconhecimento.com.br/administracao/empresa- 
Os dados encontrados na literatura publicada ocorreram conforme a proposta de Ercole; Melo e Alcoforado (2014), na qual o revisor deve procurar avaliar os resultados de maneira imparcial, procurando explicações para os resultados diferentes ou conflitantes nos diferentes estudos.

\section{ANÁLISE DOS RESULTADOS E DISCUSSÕES}

As buscas resultaram um total de 343 resultados com as palavras-chave. Foram feitas as leituras de todos os títulos e resumos e retirados os artigos que pudessem responder aos objetivos do estudo em questão, resultando assim em 10 estudos.

Desta forma, apresenta-se um quadro com o título do artigo, autores, ano de publicação (Referência), objetivo do estudo e resultados encontrados.

Quadro 1 - Artigos selecionados

\begin{tabular}{|c|c|c|}
\hline $\begin{array}{ll}\text { tulo } & \text { do } \\
\text { tigo/Referência } & \end{array}$ & S & S \\
\hline $\begin{array}{lr}\text { No caminho da } \\
\text { inovação: análise } \\
\text { das capacidades } \\
\text { inovação } \\
\text { empresas } \\
\text { diante contábeis } \\
\text { tecnologias digitais }\end{array}$ & $\begin{array}{l}\text { Examinar a capacidade de } \\
\text { inovação dos escritórios } \\
\text { de contabilidade no } \\
\text { mercado brasileiro, no uso } \\
\text { de tecnologias digitais, } \\
\text { com base nas } \\
\text { capacidades de } \\
\text { desenvolvimento, } \\
\text { operação, gestão e } \\
\text { transação de tecnologia. }\end{array}$ & $\begin{array}{l}\text { A Contabilidade se inicia no } \\
\text { caminho tradicional da } \\
\text { inovação digital, demonstrando } \\
\text { a qualidade e o valor que as } \\
\text { soluções tecnológicas podem } \\
\text { gerar quando exploradas nos } \\
\text { negócios e principalmente nos } \\
\text { processos. Esse aumento da } \\
\text { tecnologia provoca mudanças } \\
\text { nos modelos de negócios } \\
\text { contábeis. }\end{array}$ \\
\hline $\begin{array}{l}\text { dústria } \quad 4.0 \\
\text { Ianços }\end{array}$ & $\begin{array}{llll}\text { Analisar o perfil } & \text { do } \\
\text { profissional } & & \text { de }\end{array}$ & $\begin{array}{l}\text { A maior parte dos profissionais } \\
\text { tem interesse em se adequar }\end{array}$ \\
\hline
\end{tabular}

RC: 92519

Disponível em: https://www.nucleodoconhecimento.com.br/administracao/empresa- 
tecnológicos da área Contabilidade frente aos às novas tecnologias para contábil: perfil, avanços tecnológicos, atender às exigências da percepções e visando explorar a forma função. Contudo, houve expectativas dos como ele se comporta em algumas resistências às profissionais relação às novas mudanças, principalmente tendências.

entre os profissionais abaixo dos 35 anos e da área

Xavier; Carraro e societária.

Rodrigues (2020).

Características dos Diferentes Modelos de

Contábeis Negócios

em

Relação às Áreas da Contabilidade

Schiavi e Behr (2020).

As Contribuições da Contabilidade

Consultiva: Um da tecnologia

Estudo de Caso/The contabilidade bem como a Contributions of

Advisory

Accounting: A Case

Study na contabilidade consultiva.

Verificar as contribuições promovidas pelo avanço

percebem a importância da contabilidade consultiva no cenário atual assim como o papel essencial da tecnologia na profissão contábil. Os desafios abordados pelos pesquisados incluem a adaptação ao uso das novas

RC: 92519

Disponível em: https://www.nucleodoconhecimento.com.br/administracao/empresa- 


\begin{tabular}{|c|c|c|}
\hline $\begin{array}{l}\text { Angelim e Barreto } \\
\text { (2020). }\end{array}$ & & $\begin{array}{l}\text { ferramentas tecnológicas, a } \\
\text { necessidade de traçar } \\
\text { estratégias para melhor } \\
\text { atender o cliente e a } \\
\text { necessidade de conhecer a } \\
\text { gestão e o negócio de cada } \\
\text { cliente. }\end{array}$ \\
\hline $\begin{array}{ll}\text { Impact } & \text { of } \\
\text { information } & \\
\text { technology } & \text { on } \\
\text { accounting line of } & \\
\text { works } & \end{array}$ & $\begin{array}{l}\text { Determinar o impacto da } \\
\text { informação tecnologia na } \\
\text { linha de contabilidade das } \\
\text { obras no sistema global. }\end{array}$ & $\begin{array}{l}\text { Os resultados da investigação } \\
\text { mostraram que a tecnologia da } \\
\text { informação tem um substancial } \\
\text { influência na linha de trabalho } \\
\text { da contabilidade. }\end{array}$ \\
\hline $\begin{array}{l}\text { Asuquo; Dan e } \\
\text { Effiong (2020). }\end{array}$ & & \\
\hline $\begin{array}{l}\text { The impact of } \\
\text { information and } \\
\text { communication } \\
\text { technology (ICT) in } \\
\text { the accounting } \\
\text { system: advantages, } \\
\text { applications, and } \\
\text { challenges }\end{array}$ & $\begin{array}{l}\text { Examinar as vantagens } \\
\text { das aplicações da } \\
\text { tecnologia da informação } \\
\text { na contabilidade. }\end{array}$ & $\begin{array}{l}\text { A contabilidade, como a } \\
\text { linguagem dos negócios e do } \\
\text { sistema de informação, deve } \\
\text { se adaptar às novas } \\
\text { tecnologias para atender aos } \\
\text { usuários de informações } \\
\text { financeiras. Na era da } \\
\text { informação, os requisitos de } \\
\text { mercado para graduados em } \\
\text { contabilidade estão mudando } \\
\text { progressivamente. }\end{array}$ \\
\hline
\end{tabular}

RC: 92519

Disponível em: https://www.nucleodoconhecimento.com.br/administracao/empresa- 
(2020).

The Impact of Identificar se a tecnologia $A$ pesquisa mostrou que a Information teve um efeito (positivo ou velocidade e a flexibilidade são

Technology on The negativo) em aplicativos o efeito mais tecnológico nos Quality

of aplicativos de contabilidade

Accounting tecnologia da informação com características

Information

(SFAC

NO 8, 2010)

na contabilidade faz efeito aprimoradas e confiáveis.

na qualidade dos

relatórios financeiros na

Arábia Saudita.

Al Natour (2020).

A Consultoria Realizar um estudo A consultoria contábil

Contábil como documental e bibliométrico apresenta fator de retorno Oportunidade de sobre a consultoria financeiro qualitativo para as Negócios Profissionais - Um 2006 a 2016.

\section{Estudo Documental} contábil no período de empresas, consequentemente aumentando a vantagem competitiva para as mesmas.

Almeida et al (2018).

Consultoria

Organizacional como um Instrumento de Inovação em

Arranjos Produtivos Locais
Analisar como as práticas As consultoria proporcionaram inovações organizacional podem para a maioria dos negócios, desencadear inovação em sendo $89 \%$ nos processos, Arranjos Produtivos Locais $77 \%$ na gestão do negócio, (APLs).
$74 \%$ nos produtos e $40 \%$ no marketing.

RC: 92519

Disponível em: https://www.nucleodoconhecimento.com.br/administracao/empresa- 


\begin{tabular}{|c|c|c|}
\hline $\begin{array}{l}\text { ilva; Ribeiro e Silva } \\
\text { 018). }\end{array}$ & & \\
\hline $\begin{array}{l}\text { Planejamento } \\
\text { Estratégico: } \\
\text { Diagnóstico } \\
\text { Proposta de } \\
\text { Intervenção por Meio } \\
\text { de Consultoria }\end{array}$ & $\begin{array}{l}\text { Diagnosticar e apresentar } \\
\text { propostas de intervenção } \\
\text { por meio de consultoria } \\
\text { que contribua para a } \\
\text { formatação de um } \\
\text { planejamento estratégico } \\
\text { para uma empresa } \\
\text { atuante no ramo de } \\
\text { boutique de calçados e } \\
\text { acessórios femininos. }\end{array}$ & $\begin{array}{l}\text { Por meio de uma abordagem } \\
\text { de consultoria externa, uma } \\
\text { visão externa a organização, } \\
\text { verifica-se como indispensável } \\
\text { a adaptação das técnicas e } \\
\text { ferramentas ao tipo de negócio } \\
\text { que se está analisando, bem } \\
\text { como a atividade } \\
\text { desempenhada, tamanho da } \\
\text { empresa e o volume das } \\
\text { negociações. }\end{array}$ \\
\hline
\end{tabular}

Fonte: Autoria Própria

Os artigos selecionados identificaram obstáculos para o uso das tecnologias pelo contador. O Quadro 2 traz uma síntese destas dificuldades a partir da referência do artigo selecionado.

Quadro 2 - Obstáculos encontradas

\begin{tabular}{l|l} 
Título do Artigo, Referência & Obstáculos encontrados \\
$\begin{array}{l}\text { No caminho da inovação: análise das } \\
\text { capacidades de inovação de empresas }\end{array}$ & O crescente avanço tecnológico \\
contábeis diante das tecnologias & \\
digitais & \\
$\begin{array}{ll}\text { Indústria } 4.0 \text { e avanços tecnológicos } \\
\text { da área contábil: perfil, percepções e }\end{array}$ & Adequar ao uso dessas novas tecnologias \\
expectativas dos profissionais &
\end{tabular}

RC: 92519

Disponível em: https://www.nucleodoconhecimento.com.br/administracao/empresa- 
Características dos Diferentes Centralidade do papel do contador nos Modelos de Negócios Contábeis em tradicionais modelos de negócios Relação às Áreas da Contabilidade contábeis, sendo os recursos tecnológicos ainda coadjuvantes nesse cenário.

As Contribuições da Contabilidade Adaptação ao uso das novas ferramentas Consultiva: Um Estudo de Caso/The tecnológicas Contributions of Advisory Accounting:

A Case Study

Impact of information technology on Reter os gostos detectáveis, de seu accounting line of works passado enraizado no caráter e integridade

The impact of information and Gerentes de projeto inexperientes; Falta communication technology (ICT) in the de conhecimento de software; Contratos accounting system: advantages, incompletos; Falta de força de trabalho applications, and challenges especializada.

The Impact of Information Technology Meios para lidar com problemas elétricos, on The Quality of Accounting mau funcionamento da conexão com a Information (SFAC NO 8, 2010) Internet e vírus de computador.

A Consultoria Contábil como Maior duração e alocação de recursos e Oportunidade de Negócios custos de execução maiores.

Profissionais - Um Estudo Documental

Consultoria Organizacional como um Mão de obra qualificada. Instrumento de Inovação em Arranjos Produtivos Locais

RC: 92519

Disponível em: https://www.nucleodoconhecimento.com.br/administracao/empresa- 
Planejamento Estratégico: Diagnóstico Falta de conhecimento de software.

\section{e Proposta de Intervenção por Meio de}

\section{Consultoria}

\section{Fonte: Autoria Própria}

Observa-se que diversos são os obstáculos evidenciados nos artigos quando se refere ao uso das tecnologias para a consultoria contábil. Esses obstáculos provêm em sua maioria das dificuldades de muitos profissionais não se adaptarem ao uso das tecnologias em sua rotina, ou pelo profissional não estar devidamente capacitado ou qualificado, ou por medo das mudanças tecnológicas.

Schiavi et al (2020) ressalta que as tecnologias devem ser vistas como um suporte para almejar bons resultados em especial nas consultorias, todavia, o contador deve estar atento aos avanços tecnológicos que não são lentos, o que permite ao profissional ter receio de utilizar a tecnologia como suporte direcionado para a consultoria.

Xavier; Carraro e Rodrigues (2020) mencionam que a contabilidade consultiva necessita ser direcionada a partir dos meios tecnológicos, pois favorece mais segurança, precisão e confiabilidade nos dados encontrados, no entanto, para que isto aconteça, cabe ao contador estar atento às mudanças do avanço tecnológico e se adequar a todo o sistema, trazendo ao cliente tecnologias avançadas e de primeira linha.

Schiavi e Behr (2020) e Angelim e Barreto (2020) referem que uma parcela de profissionais da contabilidade ainda tem seu domínio na tradicionalidade da ciência contábil, não permitindo por total a presença das tecnologias para a melhor qualidade nos serviços da consultoria contábil, o que reflete em um atraso significativo na descoberta das tomadas de decisões.

RC: 92519

Disponível em: https://www.nucleodoconhecimento.com.br/administracao/empresa- 
Torna necessário o profissional estar atento as novas tendências tecnológicas para o melhoramento da empresa, um contador capacitado no uso de tecnologias tende a diminuir o tempo para a realização do equilíbrio da empresa, bem como também conseguem passar fidedignidade nos dados coletados.

Conforme Asuquo; Dan e Effiong (2020) a contabilidade consultiva ela traz oportunidade de expandir-se em todos os setores a de atuação da contabilidade, seja de forma gerencial, seja financeira, o que determina o trabalho da consultoria é o motivo pelo qual vai ser trabalhada a consultoria, entretanto, o enraizamento da contabilidade tradicional, cria um obstáculo enorme entre o contador e as tecnologias, onde este o profissional ainda se sente mais seguro na presença do cliente em seu escritório.

A falta de conhecimento das tecnologias e seus benefícios permeiam ainda na vida de muitos profissionais. Falta de capacitação profissional, desconhecimento sobre programas, mão de obra qualificada entre outros obstáculos permitem que as tecnologias não consigam adentrar na consultoria contábil e assim, favorecer de forma rápida, segura e eficaz, a análise dos dados e por consequente, a tomada de decisões (AL-SHAFEAY; AL_DUJAILI; AL-WATTAR, 2020; ALMEIDA et al., 2018; SILVA; RIBEIRO; SILVA, 2018; GAFURI, ROJO; MIURA, 2017).

Entretanto, os obstáculos não somente se relacionam as dificuldades dos contadores no uso das tecnologias, o mau funcionamento dos programas, a lentidão da internet, vírus no computador podem influenciar a não adesão do profissional ao meio das tecnologias para auxílio na contabilidade consultiva (AL NATOUR, 2020).

A utilização de Softwares e Hardwares requer uma intensa dedicação do profissional para poder o mesmo saber utilizar as ferramentas e com isso apresentar métodos que possam trazer custos mais baixos e maiores benefícios para a empresa. Considerando estes obstáculos em suas complexidades do meio tecnológico,

RC: 92519

Disponível em: https://www.nucleodoconhecimento.com.br/administracao/empresa- 
identifica-se as potencialidades que as tecnologias podem trazer a consultoria contábil.

Quadro 3 - Potencialidades para a consultoria contábil e o uso de tecnologias

Título do Artigo, Referência

No caminho da inovação: análise das capacidades de inovação de empresas contábeis diante das tecnologias digitais Indústria 4.0 e avanços tecnológicos Agilidade e ganho de tempo. da área contábil: perfil, percepções e Comodidade. expectativas dos profissionais

Características dos Diferentes A utilização de meios tecnológicos usuais Modelos de Negócios Contábeis em como e-mails, telefone, entre outros para Relação às Áreas da Contabilidade

As Contribuições da Contabilidade Relação indissociável entre a tecnologia e Consultiva: Um Estudo de Caso/The Contributions of of Advisory

Accounting: A Case Study

Impact of information technology on accounting line of works

\section{Potencialidades}

Utilização de diferentes tecnologias digitais; atuar totalmente online para trazer mais acessibilidade e agilidade no fornecimento dos serviços contábeis realizar a consultoria contábil.

a contabilidade consultiva promovendo suporte ágil e de qualidade aos seus diversos usuários.

Satisfazer seus públicos interno e externo por dando-lhes serviços de qualidade e desempenho, em um base contínua e consistente.

The impact of information and Satisfação do cliente; Agilidade; communication technology (ICT) in Confiabilidade.

the accounting system: advantages, applications, and challenges

The Impact of Information Velocidade e flexibilidade Technology on The Quality of

RC: 92519

Disponível em: https://www.nucleodoconhecimento.com.br/administracao/empresa- 
Accounting Information (SFAC NO 8, 2010)

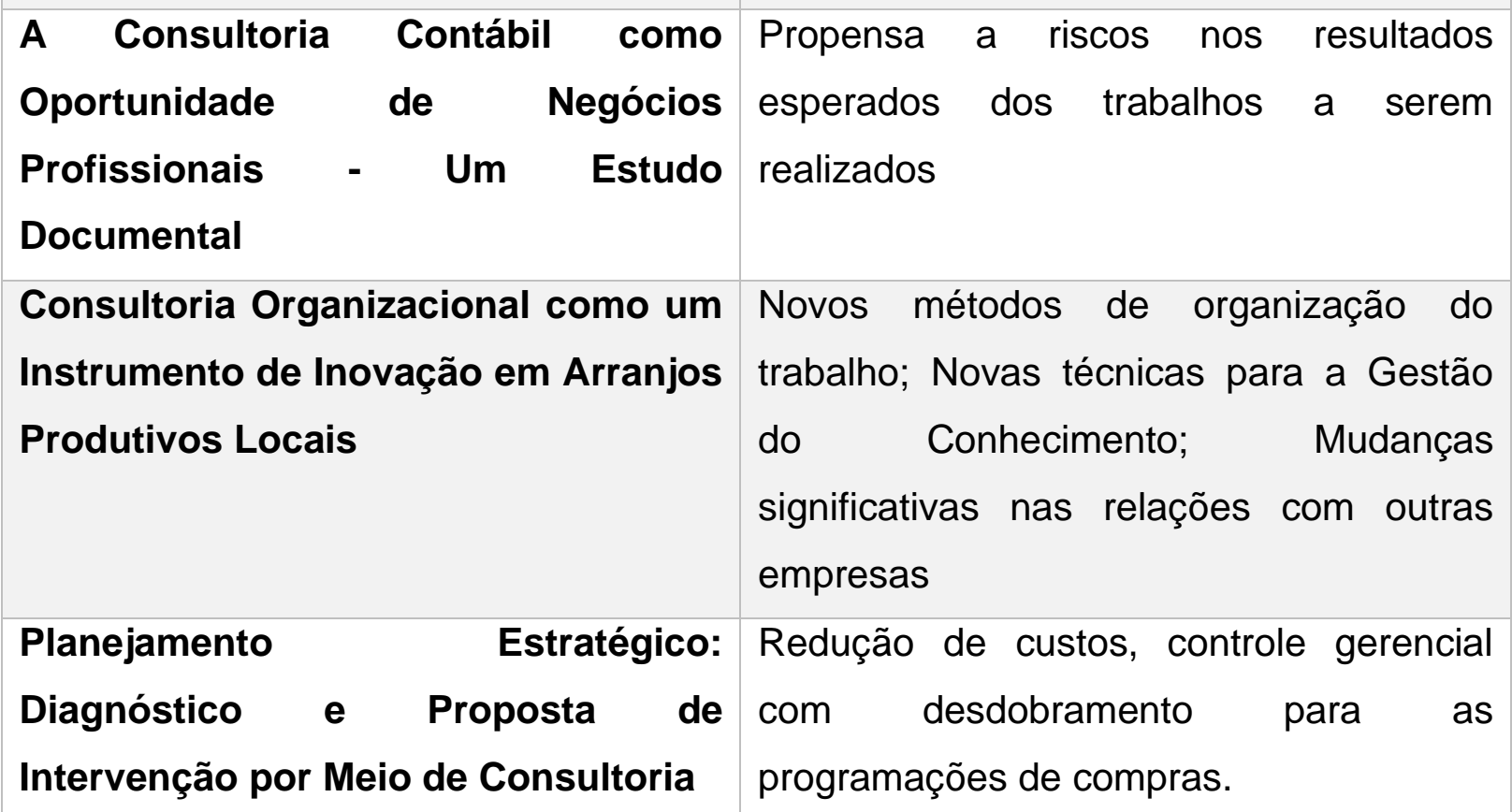

Fonte: Autoria Própria

Evidente que a necessidade de se aprofundar em novos conceitos e conhecimentos é de suma importância para os profissionais de contábeis, para tanto, observa-se as potencialidades das tecnologias sobre a consultoria contábil. A contabilidade é considerada como uma ferramenta fundamental de apoio ao crescimento da empresa, todavia, a falta de conhecimento das tecnologias pelo contador faz com que este conhecimento adquirido seja identificado na tradicionalidade dos papéis.

Schiavi et al. (2020) mencionam várias potencialidades que as tecnologias podem favorecer a consultoria contábil, citam-se: Utilização de diferentes tecnologias digitais; atuar totalmente online para trazer mais acessibilidade e agilidade no fornecimento dos serviços contábeis. Estas colocações pelos autores identificam a importância da contabilidade e das tecnologias andarem sempre ao lado da outra, o que favorece ao contador fidelização dos seus clientes.

RC: 92519

Disponível em: https://www.nucleodoconhecimento.com.br/administracao/empresa- 
Xavier; Carraro e Rodrigues (2020) corroboram com os autores acima sobre as potencialidades das tecnologias para a consultoria contábil e reforçam que além destas colocações também pode ser mencionado à agilidade, o ganho de tempo e a comodidade tanto da empresa como do contador.

Para Schiavi e Behr (2020) utilizar as tecnologias para realizar a consultoria contábil não se relaciona somente às questões de programas computacionais, o telefone, as redes sociais, os e-mails, entre outras tecnologias podem auxiliar o contador tradicional a realizar sua consultoria sem necessariamente ter quer trabalhar com programas.

Segundo Angelim e Barreto (2020) as tecnologias já têm sua participação na contabilidade consultiva, todavia, a presença de programas facilitadores para a realização da consultoria contábil deu norteamento ao que se chama tecnologia da inovação, trazendo agilidade e mais confiabilidade nos dados apresentados.

Conforme Asuquo; Dan e Effiong (2020) e Al-Shafeay; Al Dujaili e Al-Wattar (2020), a contabilidade consultiva tem o objetivo de fornecer as mais fidedignas informações sobre a empresa e os resultados que ela obtiver, a satisfação do cliente por trazer serviços de qualidade e desempenho é que demonstra a diferença da presença da tecnologia mais avançada para o contador.

Al Natour (2020) que as tecnologias se apresentam velozes e flexíveis, duas condições essenciais para o trabalho do contador que em sua consultoria o tempo se torna um inimigo para a tomada de decisões, já que o mercado competitivo está cada vez mais exigente em relação às empresas.

Segundo Almeida et al. (2018) as tendências para aumentar o lucro de uma empresa impactam diretamente no contador, o que intensifica o conhecimento da contabilidade em correr riscos. As tecnologias atuam de forma a garantir menor risco

RC: 92519

Disponível em: https://www.nucleodoconhecimento.com.br/administracao/empresa- 
para o contador e melhor rentabilidade à empresa, o que permite ao cliente e ao dono de empresa um serviço de qualidade e em tempo ágil.

Silva; Ribeiro e Silva (2018) e Gafuri; Rojo e Miura (2017) enfatizam que além de fornecer uma análise precisa e segura, as tecnologias também fornecem métodos de organização de trabalho, gestão de conhecimento, melhor relação com demais empresas, controle nos custos, um aprimoramento na tomada de decisão, entre outras potencialidades objetivando uma maior produtividade com custos menores em relação às técnicas tradicionais e manuais.

Percebe-se que as tecnologias aliadas à contabilidade consultiva têm várias potencialidades o que permite que a contabilidade possa ter sua tomada de decisão para que a empresa não corra problemas financeiros e nem saia do mercado competitivo, atuando em cima do problema evidenciado.

\section{CONSIDERAÇÕES FINAIS}

Os obstáculos para o uso das tecnologias na contabilidade consultiva não deixam de ser algo preocupante, tendo em vista que o profissional contador deve ter como auxílio a tecnologia para melhorar o seu serviço e que a não aceitação do uso das tecnologias pode fazer com que este profissional seja desqualificado e desacreditado de suas atribuições.

O profissional da contabilidade deve ter em mente práticas sustentáveis para conseguir angariar mais benefícios financeiros e operacionais para as empresas, tendo em vista que além do alto custo de aquisição e manutenção de todo o processo de instalação tecnológica, existem gastos quanto a qualificação e a capacitação profissional.

A crescente demanda de programas computacionais influenciam diretamente na não aceitação de muitos profissionais, isso pode ser considerado de forma desvantajosa

RC: 92519

Disponível em: https://www.nucleodoconhecimento.com.br/administracao/empresa- 
para a contabilidade, já que não se dispõe de um único sistema para realizar as atividades necessárias que a contabilidade necessita.

Mas as potencialidades que os avanços tecnológicos trazem para a consultoria contábil são imensos, podendo estas potencialidades gerarem impactos positivos no que se refere a aceitação do uso das tecnologias para o alcance das metas na contabilidade. Neste contexto, tem-se que as tecnologias facilitam a visão geral do contador, em que a percepção de uma margem menor de erro e acesso a todos os dados de seu interesse que possam ser compilados e/ou faturados, encontra na tecnologia uma aliada para realizar um serviço de excelência.

Considera-se, portanto, que o estudo atinge seu objetivo elencado e remete como lacuna a pesquisa realizada baseada na consultoria contábil de forma geral, o que abre caminhos para que seja idealizado novas pesquisas estendendo este tema para uma forma mais restrita como a consultoria contábil financeira ou mesmo gerencial.

\section{REFERÊNCIAS}

ALMEIDA, Leonardo Soares Francisco de et al. A Consultoria Contábil como Oportunidade de Negócios Profissionais-um Estudo Documental. Pensar Contábil, v. 20, n. $72,2018$.

AL NATOUR, Jihad Rebhee Abdel Qader et al. The Impact of Information Technology on The Quality of Accounting Information (SFAC NO 8, 2010). Turkish Journal of Computer and Mathematics Education (TURCOMAT), v. 12, n. 13, p. 885-903, 2020.

AL-SHAFEAY, Karrar Mohammed; AL_DUJAILI, Mohammed Jawad; AL-WATTAR, Yasir Mohammed Ali. The impact of Information and Communication Technology

RC: 92519

Disponível em: https://www.nucleodoconhecimento.com.br/administracao/empresa- 
(ICT) In the accounting system: advantages, applications, and challenges. PalArch's Journal of Archaeology of Egypt/Egyptology, v. 17, n. 6, p. 15814-15825, 2020.

ANGELIM, Vitória Ribeiro; BARRETO, Tayssa Vieira. As Contribuições da Contabilidade Consultiva: Um Estudo de Caso/The Contributions of Advisory Accounting: A Case Study. ID on line Revista de Psicologia, v. 14, n. 52, p. 317$331,2020$.

ASUQUO, Akabom I.; DAN, Nicholas O.; EFFIONG, Glory T. Impact of information technology on accounting line of works. International Journal of Recent Technology and Engineering, v. 9, n. 2, p. 1572-1577, 2020.

DE ANDRADE SIMÕES, Maervelym Pâmella et al. Benefícios do uso da tecnologia Blockchain como instrumento para a auditoria contábil. Revista ambiente contábilUniversidade Federal do Rio Grande do Norte-ISSN 2176-9036, v. 13, n. 1, p. 3953, 2021.

ERCOLE, Flávia Falci; MELO, Laís Samara de; ALCOFORADO, Carla Lúcia Goulart Constant. Revisão integrativa versus revisão sistemática. Revista Mineira de Enfermagem, v. 18, n. 1, p. 9-12, 2014.

FERREIRA, Tiago Janes et al. Automação contábil: tecnologia em contabilidade sob a ótica da teoria institucional. XI Congresso ANPCONT. 3 a 6 de junho de 2017. Belo Horizonte, Minas Gerais.

GAFURI, Raquel Adriana Pin; ROJO, Cláudio Antonio; MIURA, Marcio Nakayama. Planejamento estratégico: diagnóstico e proposta de intervenção por meio de consultoria. Revista Capital Científico-Eletrônica (RCCe)-ISSN 2177-4153, v. 15, n. 1, p. 139-155, 2017.

MARION, JOSE CARLOS; RIBEIRO, OSNI MOURA. Introdução à contabilidade gerencial. Saraiva Educação SA, 2017. Disponível em:

RC: 92519

Disponível em: https://www.nucleodoconhecimento.com.br/administracao/empresa- 
https://books.google.com.br/books?hl=pt-

$B R \& \mid r=\& i d=k D 1 n D w A A Q B A J \& o i=f n d \& p g=P T 5 \& d q=$ Introdu\%C3\%A7\%C3\%A3o+\%C 3\%A0+contabilidade+gerencial.+\&ots=JjrSnq2mD0\&sig=vcUiQXgi1UkNhLanfgWU67 QVgas\#v=onepage\&q=Introdu\%C3\%A7\%C3\%A30\%20\%C3\%A0\%20contabilidade\% 20gerencial.\&f=false

SAMPAIO, Rosana Ferreira; MANCINI, Marisa Cotta. Estudos de revisão sistemática: um guia para síntese criteriosa da evidência científica. Brazilian Journal of Physical Therapy, v. 11, p. 83-89, 2007.

SCHIAVI, Giovana Sordi; BEHR, Ariel. Características dos diferentes modelos de negócios contábeis em relação às áreas da Contabilidade. REUNIR Revista de Administração Contabilidade e Sustentabilidade, v. 10, n. 3, p. 47-59, 2020.

SCHIAVI, Giovana Sordi et al. No caminho da inovação: análise das capacidades de inovação de empresas contábeis diante das tecnologias digitais. Revista Brasileira de Gestão de Negócios, v. 22, p. 381-405, 2020.

SILVA, Gustavo Oliveira et al. O impacto da tecnologia na profissão contábil sob perspectivas de pessoas com formação e/ou experiência profissional na área. Contribuciones a las Ciencias Sociales, n. 72, p. 3, 2020.

SILVA, Fabiana Ferreira; RIBEIRO, Ana Regina Bezerra; SILVA, Washington Ferreira. Consultoría Organizacional como um Instrumento de Inovação em arranjos produtivos locais. Revista Organizações em Contexto, v. 14, n. 27, p. 29-52, 2018.

VILLA, Patricia et al. O monólogo contábil: uma análise do uso da contabilidade gerencial em micro e pequenas empresas à luz do processo comunicacional segundo Bakhtin”. Monografia para obtenção de título de mestrado em contabilidade. UFPR, 2012.

RC: 92519

Disponível em: https://www.nucleodoconhecimento.com.br/administracao/empresa- 
XAVIER, Leonardo Montes; CARRARO, Wendy Beatriz Witt Haddad; RODRIGUES, Ana Tércia Lopes. Indústria 4.0 e avanços tecnológicos da área contábil: perfil, percepções e expectativas dos profissionais. Contexto. Porto Alegre, RS. Vol. 20, n. 45 (maio/ago. 2020), p. 34-50, 2020.

Enviado: Julho, 2021.

Aprovado: Julho, 2021.

RC: 92519

Disponível em: https://www.nucleodoconhecimento.com.br/administracao/empresavia-tecnologia 